\title{
Clinical efficacy of mineralized collagen (MC) versus anorganic bovine bone (Bio-Oss) for immediate implant placement in esthetic area: a single-center retrospective study
}

Yan Dai ${ }^{1 \dagger}$, Jin Xu ${ }^{2 \dagger}$, Xiao-Hui Han ${ }^{3}$, Fu-Zhai Cui ${ }^{4}$, Dong-Sheng Zhang ${ }^{5^{*}}$ and Sheng-Yun Huang ${ }^{5^{*}}$

\begin{abstract}
Background: The purpose of this retrospective study was to evaluate the clinical efficacy of mineralized collagen (MC) versus anorganic bovine bone (Bio-Oss) for immediate implant placement in esthetic area.

Methods: Medical records of Department of Oral and Maxillofacial Surgery of Shandong Provincial Hospital were screened for patients who had been treated with immediate implant implantation in the esthetic area using either MC (Allgens ${ }^{\circledR}$, Beijing Allgens Medical Science and Technology Co., Ltd., China) or Bio-Oss (Bio-Oss ${ }^{\circledR}$, Geistlich Biomaterials, Wolhusen, Switzerland), between January 2018 and December 2019. All patients fulfilling the in-/exclusion criteria and following followed for a minimum period of 1 year after surgery were enrolled into the presented study. Implant survival rate, radiographic, esthetic and patient satisfactory evaluations were performed.

Results: Altogether, 70 patients were included in the study; a total of 80 implants were inserted. All implants had good initial stability. The survival rate of implants was $100 \%$ at 1 -year follow-up. The differences in horizontal and vertical bone loss between the MC group $(0.72 \pm 0.26 \mathrm{~mm}, 1.62 \pm 0.84 \mathrm{~mm})$ and the Bio-Oss group $(0.70 \pm 0.52 \mathrm{~mm}$, $1.57 \pm 0.88 \mathrm{~mm}$ ) were no significant difference statistically no significant 6 months after permanent restoration. Similar results occurred at 12 months after permanent restoration functional loaded. Clinical acceptability defined by pink esthetic score $(P E S) \geq 6(6.07 \pm 1.62$ vs. $6.13 \pm 1.41)$ was not significantly different between groups. Patient satisfaction estimated by visual analog scale (VAS) was similar ( $8.56 \pm 1.12 \mathrm{vs} .8 .27 \pm 1.44)$, and the difference was no significant difference between the two groups.
\end{abstract}

Conclusions: The biomimetic MC showed a similar behaviour as Bio-Oss not only in its dimensional tissues changes but also in clinical acceptability and patient satisfaction. Within the limitations of this study, these cases show that MC could be considered as an alternative bone graft in IIP

Keywords: Mineralized collagen, Immediate implant implantation, Osseointegration

*Correspondence: ds63zhang@sdu.edu.cn; huangsy28@163.com

†Yan Dai and Jin Xu have contributed equally to this work

${ }^{5}$ Department of Oral and Maxillofacial Surgery, Shandong Provincial

Hospital Affiliated to Shandong First Medical University, Jinan 250021,

Shandong, China

Full list of author information is available at the end of the article

\section{Background}

To simplify the surgical procedures and treatment time, clinicians and researchers have developed a new implant placement protocol, defined as "immediate implant implantation (IIP)" [1]. As the name implies, IIP means that placing a dental implant immediately into fresh extraction sockets. Since the first report 
of IIP published in 1976, the interest for this technique has gradually increased [2]. Studies suggest that IIP may provide some advantages, such as preventing alveolar ridge absorption, maintaining the width and height of alveolar crest, getting satisfactory esthetic results. Finally, the implant can be seated in the ideal anatomical position according with the biomechanics [3-14]. Furthermore, several clinical Studies have shown that that similar implant survival rates are independent of the timing of implant placement [15-17]. Based on the systematic review, patients prefer short treatment protocols to conventional implant placement [18]. Consequently, IIP is recognized by clinicians nowadays. However, the size of the implant do not completely fit with the socket, and particularly, the residual gap between the implants and the labial alveolar cannot fulfill a tight closure affecting the success of IIP. The gap provides sufficient space to fill the bone defect between the labial bone wall and the exposed implant surface with suitable bone filler, and it also provides space for formatting of a blood clot, which can subsequently restructure into a provisional matrix of connective tissue that support the newly-formed woven bone. Pro.Tarnow recommended to place a bone graft into the residual labial gap around a postextraction socket anterior implant. It's helpful for limiting the amount of facial-palatal contour change in IIP [19]. Various bone graft materials have been employed around IIP for bone augmentation aiming to promote the tissue which contained osteogenic cells to fill out the defect area [20]. Bone grafting materials, categorized into autogenous, allografts, xenografts, and alloplasts, have been applied to fill the osseous gap around the implant [21]. Till date, no literature has proved that one material is superior to another [22-25].

MC designed by Cui et al. is a novel form of artificial bone graft, which consists of orderly arranged type I collagen and nano-hydroxyapatite (HA) [26]. It contains approximately $45 \%$ mineral by weight. This material possesses excellent biological histocompatibility and osseointegration with a capability of biomimetic composition and microstructure similar to the natural bone tissue. As demonstrated in previous studies, MC had been successfully applied for bone defect repair in a wide range. Peng et al. observed the effect of MC for the treatment of senile proximal humeral osteoporotic fractures, proving that it can accelerate healing of senile proximal humeral fracture, improve the therapeutic effect and reduce the complications [27]. Feng et al. reported that MC showed better effect on new bone regeneration in alveolar ridge preservation [28]. Based the recognition of $\mathrm{MC}$, we assessed the first application of MC in IIP using retrospective data. Herein, the purpose of this study was to evaluate the therapeutic effect of $\mathrm{MC}$ by radiological analysis. We hypothesized that application MC would achieve a satisfactory clinical outcomes in IIP.

\section{Methods \\ Study design; in-/exclusion criteria}

Medical records were selected among those patients who had been treated with immediate post-extraction implants and performed GBR protocol using bone grafting either MC (Allgens ${ }^{\circledR}$, Beijing Allgens Medical Science and Technology Co., Ltd., China) or Bio-Oss (Bio-Oss ${ }^{\circledR}$, Geistlich Biomaterials, Wolhusen, Switzerland) at the Department of oral and maxillofacial surgery of Shandong Provincial Hospital Affiliated to Shandong University (Jinan, Shandong Province, China), in the period between January 2018 and December 2019.

\section{Inclusion criteria}

(1) Aged $\geq 18$.

(2) Class I and class II B of Gluckman's classification [29].

(3) No acute infection at the extraction site [30].

(4) Sufficient volume of apical and palatal bone at the extraction site to allow implant placement in a correct 3D position with primary stability [30].

(5) Good general health.

(6) Good oral hygiene.

Especially, patients included in this study had to be followed for a minimum period of 1 year after surgery.

\section{Exclusion criteria}

(1) Contraindication for surgery such as uncontrolled diabetes, pregnancy, previous or current radiation or immunosuppressive therapy.

(2) Smoking (over ten cigarettes per day) and excessive drinking.

(3) Patients with any systemic disease that could affect bone healing were excluded from the study.

Patients were divided into two groups: the MC group who were grafted with MC and the Bio-Oss group with Bio-Oss. All the treatments were arranged consecutively at the Department of Oral maxillofacial surgery of Shandong Provincial Hospital Affiliated to Shandong University. Patients were informed about the treatment purpose, process, and the possible risks of this study, and then signed the informed consent. 


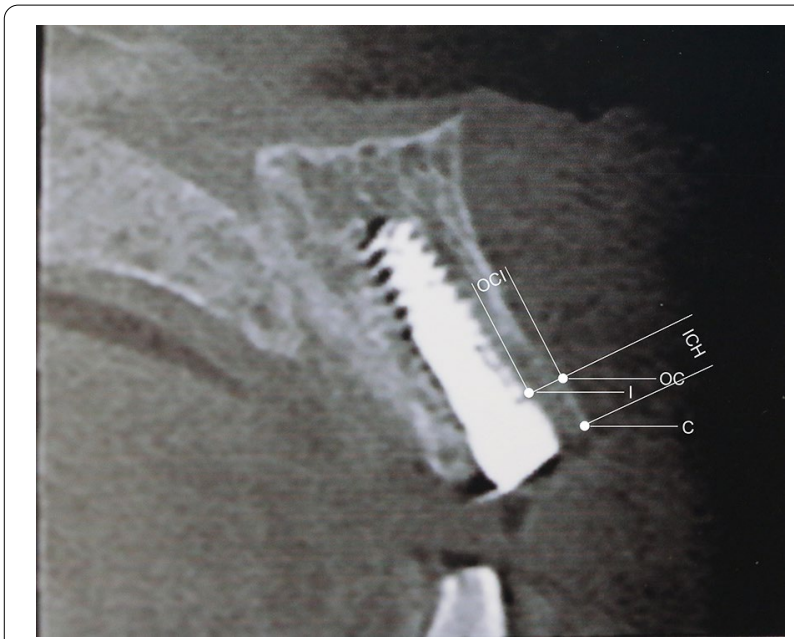

Fig. 1 Illustration of radiographic measurement

\section{Surgical procedure}

In order to evaluate the extraction sites, clinical examination and $\mathrm{CBCT}$ were taken for each patient. Periodontal treatment and oral hygiene instructions were treated to all patients for better oral environment. Each patient was received antibiotics (Roxithromycin Capsules of $150 \mathrm{mg}$ ) $1 \mathrm{~h}$ before surgery and rinsed with $0.2 \%$ chlorhexidine gluconate for $1 \mathrm{~min}$.

All patients were performed by Dr. Huang. Articaine (4\% articaine with 1:100,000 epinephrine) was used as local anesthetic. A flap was designed with the implant site followed by sulcular incisions on the buccal and palatal that extends one tooth to the mesial and distal without vertical incisions. The flap didn't exceed the mucogingival junction. The tooth was extracted using atraumatic extraction technique and the granulation tissue was carefully removed with curette. Following the instructions of implant manufacturer, the preparation of the implant site was performed rinsed with abundant sterile saline. The pilot drill was conducted to the palatal wall. According to socket size, implant diameter was determined to achieve $>1.5 \mathrm{~mm}$ mesio-distal implant distance and the length of implant was $11-13 \mathrm{~mm}$. The implant was inserted with $35 \mathrm{Ncm}$ or more and $1 \mathrm{~mm}$ below the most apical bone peak. Then the healing abutment was placed. In all cases (not related to the socket configuration or defect morphology), bone substitute material was applied in the residual gap. In MC group, surgery was performed using MC, while Bio-Oss group was placed with Bio-Oss. CBCT (ProMax 3D, Planmeca OY, 00880 Helsinki, Finland) scans for each patient were performed to confirm proper implant placement after surgery.
Patients were postoperatively instructed to take roxithromycin $(150 \mathrm{mg} \times 2 /$ day for $5-7$ days $)$ and $0.2 \%$ chlorhexidine gluconate twice a day for 14 days.

\section{Restorative procedure}

The reconstructive treatment protocol was performed 6 months after implantation. The patients were scheduled to take CBCT to observe the alveolar bone change. Standard implant impression was made using silicon rubber impression material (DMG, Hamburg, Germany) for permanent restorations. All clinical procedures of permanent restoration were operated by Dr. Han.

\section{Clinical follow-up}

The time immediately postsurgery, 6 months and 12 months after permanent restoration were respectively set as T1, T2, and T3. Patients were recalled at T3 to record implant survival rate and give a clinical examination.

\section{Evaluation criteria and methods Implant survival and complications}

Implant survival and complications were observed at 12 months after the final crown delivery. According to Buser's criteria for successful implant osseointegration [31], the success criteria are as follows:

- No persistent subjective complaints, such as pain, and/or paresthesia

- No recurrent peri-implant infection with suppuration

- No mobility

- No continuous radiolucency around the implant

- Possibility for restoration

\section{Radiographic measurements}

CBCT was scheduled to assess the osseointegration process at T1, T2, and T3 followed by Yang et al. [32]. Specific fixed reference points were selected in the images to obtain the same tri-dimensional position of the measurement axis. The reference landmarks were defined as follows.

- Implant shoulder (I).

- Top of the bone crest (C).

- Implant shoulder to labial bone crest (OC).

- Horizontal distance between OC and I (OCI).

- Vertical distance between I and C (ICH). 
Dimension changes of labial bone were measured by $\mathrm{OCI}$ and $\mathrm{ICH}$ at T2and T3 compared to T1. This measure defined as $\triangle \mathrm{OCI}$ and $\triangle \mathrm{ICH}$ was taken at least three times, and the mean values were recorded (Fig. 1).

\section{Esthetic assessment}

All 70 patients were scheduled to recall at T3. A digital camera (Canon 6D, Canon Inc., Tokyo, Japan) was used with the same parameters to obtain standardized digital photographic records which were taken at the occlusal plane and centered at the contact region of the upper incisors.

The esthetic outcome and performance were evaluate by the pink esthetic score (PES) described by Belser et al. [33]. The PES contains the following five variables: mesial papilla, distal papilla, curvature of the facial mucosa, level of the facial mucosa, root convexity/soft tissue color and texture at the facial aspect of the implant site. A score of 2, 1, or 0 is assigned to the parameters above. Thus, the maximum score for optimal soft tissue is 10 . The PES was objectively

Table 1 Demographic information of the MC group

\begin{tabular}{|c|c|c|c|c|c|}
\hline Patient no & Implant brand & Implant site & Implant dimension (mm) & $\begin{array}{l}\text { Insertion torque } \\
\text { (Ncm) }\end{array}$ & $\begin{array}{l}\text { healing } \\
\text { abutment/ } \\
\text { temporary crown }\end{array}$ \\
\hline 1 & $\mathrm{XIVE}^{\circledR}$ & 1121 & $3.8 \times 133.8 \times 13$ & 35 & Temporary crown \\
\hline 2 & NobelActive $^{\circledR}$ & 11 & $4.3 \times 13$ & 35 & Temporary crown \\
\hline 3 & $\mathrm{XIVE}^{\circledR}$ & 11 & $3.8 \times 13$ & 30 & Healing abutment \\
\hline 4 & $\mathrm{XIVE}^{\circledR}$ & 21 & $3.8 \times 13$ & 35 & Temporary crown \\
\hline 5 & $\mathrm{XIVE}^{\circledR}$ & 11 & $3.8 \times 13$ & 30 & Healing abutment \\
\hline 6 & NobelActive $^{\circledR}$ & 22 & $3.5 \times 11.5$ & 35 & Temporary crown \\
\hline 7 & $\mathrm{XIVE}^{\circledR}$ & 11 & $3.8 \times 13$ & 40 & Temporary crown \\
\hline 8 & NobelActive ${ }^{\circledR}$ & 21 & $3.8 \times 11$ & 35 & Temporary crown \\
\hline 9 & $\mathrm{XIVE}^{\circledR}$ & 11 & $3.8 \times 13$ & 35 & Temporary crown \\
\hline 10 & NobelActive $^{\circledR}$ & 212223 & $4.3 \times 11.54 .3 \times 11.5$ & 35 & Temporary crown \\
\hline 11 & $\mathrm{XIVE}^{\circledR}$ & 21 & $3.8 \times 13$ & 35 & Temporary crown \\
\hline 12 & NobelActive $^{\circledR}$ & 21 & $4.3 \times 13$ & 25 & Healing abutment \\
\hline 13 & NobelActive ${ }^{\circledR}$ & 1121 & $4.3 \times 11.54 .3 \times 11.5$ & 35 & Temporary crown \\
\hline 14 & $\mathrm{XIVE}^{\circledR}$ & 12 & $3.4 \times 11$ & 35 & Temporary crown \\
\hline 15 & NobelActive $^{\circledR}$ & 12 & $3.4 \times 11.5$ & 35 & Temporary crown \\
\hline 16 & $\mathrm{XIVE}^{\circledR}$ & 1121 & $3.8 \times 133.8 \times 13$ & 35 & Temporary crown \\
\hline 17 & $\mathrm{XIVE}^{\circledR}$ & 11 & $3.8 \times 13$ & 30 & Healing abutment \\
\hline 18 & $\mathrm{XIVE}^{\circledR}$ & 21 & $3.8 \times 13$ & 40 & Temporary crown \\
\hline 19 & NobelActive $^{\circledR}$ & 21 & $4.3 \times 11.5$ & 35 & Temporary crown \\
\hline 20 & NobelActive ${ }^{\circledR}$ & 11 & $3.5 \times 13$ & 30 & Healing abutment \\
\hline 21 & $\mathrm{XIVE}^{\circledR}$ & 12 & $3.8 \times 11$ & 35 & Temporary crown \\
\hline 22 & $\mathrm{XIVE}^{\circledR}$ & 11 & $3.8 \times 13$ & 25 & Healing abutment \\
\hline 23 & $\mathrm{XIVE}^{\circledR}$ & 12 & $3.4 \times 13$ & 30 & Temporary crown \\
\hline 24 & $\mathrm{XIVE}^{\circledR}$ & 2122 & $3.8 \times 133.4 \times 13$ & 30 & Temporary crown \\
\hline 25 & NobelActive $^{\circledR}$ & 13 & $4.3 \times 13$ & 35 & Healing abutment \\
\hline 26 & $\mathrm{XIVE}^{\circledR}$ & 11 & $3.8 \times 13$ & 35 & Temporary crown \\
\hline 27 & NobelActive ${ }^{\circledR}$ & 21 & $43 \times 13$ & 30 & Healing abutment \\
\hline 28 & NobelActive $^{\circledR}$ & 22 & $3.5 \times 11.5$ & 30 & Healing abutment \\
\hline 29 & $\mathrm{XIVE}^{\circledR}$ & 12 & $3.4 \times 11$ & 35 & Healing abutment \\
\hline 30 & $\mathrm{XIVE}^{\circledR}$ & 21 & $3.8 \times 13$ & 35 & Temporary crown \\
\hline 31 & $\mathrm{XIVE}^{\circledR}$ & 12 & $3.8 \times 11$ & 35 & Temporary crown \\
\hline 32 & $\mathrm{XIVE}^{\circledR}$ & 11 & $3.8 \times 13$ & 25 & Healing abutment \\
\hline 33 & $\mathrm{XIVE}^{\circledR}$ & 21 & $3.4 \times 13$ & 30 & Healing abutment \\
\hline 34 & $\mathrm{XIVE}^{\circledR}$ & 11 & $3.8 \times 13$ & 35 & Temporary crown \\
\hline 35 & $\mathrm{XIVE}^{\circledR}$ & 11 & $3.8 \times 13$ & 35 & Temporary crown \\
\hline
\end{tabular}


Table 2 Demographic information of the Bio-oss group

\begin{tabular}{|c|c|c|c|c|c|}
\hline Patient no & Implant brand & Implant site & Implant dimension $(\mathrm{mm})$ & $\begin{array}{l}\text { Insertion torque } \\
(\mathrm{Ncm})\end{array}$ & $\begin{array}{l}\text { Healing } \\
\text { abutment/ } \\
\text { temporary crown }\end{array}$ \\
\hline 1 & NobelActive ${ }^{\circledR}$ & 11 & $4.3 \times 11.5$ & 35 & Temporary crown \\
\hline 2 & NobelActive ${ }^{\circledR}$ & 21 & $4.3 \times 13$ & 35 & Temporary crown \\
\hline 3 & XIVE ${ }^{\circledR}$ & 21 & $3.8 \times 13$ & 35 & Temporary crown \\
\hline 4 & XIVE ${ }^{\circledR}$ & 1121 & $3.8 \times 133.8 \times 13$ & 35 & Temporary crown \\
\hline 5 & NobelActive ${ }^{\circledR}$ & 22 & $3.5 \times 11.5$ & 35 & Temporary crown \\
\hline 6 & $\mathrm{XIVE}^{\circledR}$ & 11 & $3.8 \times 13$ & 30 & Healing abutment \\
\hline 7 & XIVE ${ }^{\circledR}$ & 11 & $3.8 \times 13$ & 35 & Temporary crown \\
\hline 8 & $X I V E^{\circledR}$ & 1121 & $3.8 \times 133.8 \times 13$ & 30 & Healing abutment \\
\hline 9 & XIVE ${ }^{\circledR}$ & 21 & $3.8 \times 13$ & 35 & Temporary crown \\
\hline 10 & XIVE $^{\circledR}$ & 12 & $3.8 \times 13$ & 35 & Temporary crown \\
\hline 11 & NobelActive ${ }^{\circledR}$ & 2122 & $4.3 \times 11.54 .3 \times 11.5$ & 35 & Temporary crown \\
\hline 12 & XIVE ${ }^{\circledR}$ & 11 & $3.8 \times 13$ & 40 & Temporary crown \\
\hline 13 & XIVE ${ }^{\circledR}$ & 21 & $3.8 \times 13$ & 40 & Temporary crown \\
\hline 14 & NobelActive ${ }^{\circledR}$ & 21 & $4.3 \times 11.5$ & 35 & Temporary crown \\
\hline 15 & XIVE $^{\circledR}$ & 12 & $3.8 \times 11$ & 35 & Temporary crown \\
\hline 16 & XIVE ${ }^{\circledR}$ & 11 & $3.8 \times 13$ & 25 & Healing abutment \\
\hline 17 & NobelActive ${ }^{\circledR}$ & 11 & $4.3 \times 13$ & 35 & Temporary crown \\
\hline 18 & XIVE ${ }^{\circledR}$ & 21 & $3.8 \times 13$ & 35 & Temporary crown \\
\hline 19 & XIVE ${ }^{\circledR}$ & 1121 & $3.8 \times 133.8 \times 13$ & 35 & Temporary crown \\
\hline 20 & XIVE ${ }^{\circledR}$ & 11 & $3.8 \times 13$ & 30 & Healing abutment \\
\hline 21 & XIVE ${ }^{\circledR}$ & 11 & $3.8 \times 13$ & 25 & Healing abutment \\
\hline 22 & XIVE $^{\circledR}$ & 22 & $3.4 \times 13$ & 30 & Healing abutment \\
\hline 23 & NobelActive ${ }^{\circledR}$ & 13 & $4.3 \times 13$ & 35 & Temporary crown \\
\hline 24 & NobelActive ${ }^{\circledR}$ & 12 & $3.5 \times 11.5$ & 30 & Healing abutment \\
\hline 25 & XIVE ${ }^{\circledR}$ & 22 & $3.4 \times 11$ & 35 & Healing abutment \\
\hline 26 & NobelActive ${ }^{\circledR}$ & 21 & $3.8 \times 11$ & 35 & Temporary crown \\
\hline 27 & NobelActive ${ }^{\circledR}$ & 21 & $43 \times 13$ & 30 & Healing abutment \\
\hline 28 & XIVE $^{\circledR}$ & 21 & $3.8 \times 13$ & 35 & Temporary crown \\
\hline 29 & $X_{I V E}{ }^{\circledR}$ & 12 & $3.8 \times 11$ & 35 & Temporary crown \\
\hline 30 & XIVE ${ }^{\circledR}$ & 11 & $3.8 \times 13$ & 25 & Healing abutment \\
\hline 31 & NobelActive ${ }^{\circledR}$ & 12 & $3.5 \times 11.5$ & 35 & Temporary crown \\
\hline 32 & XIVE ${ }^{\circledR}$ & 1113 & $3.8 \times 133.8 \times 13$ & 35 & Healing abutment \\
\hline 33 & XIVE $^{\circledR}$ & 11 & $3.8 \times 11$ & 35 & Temporary crown \\
\hline 34 & NobelActive ${ }^{\circledR}$ & 21 & $3.5 \times 13$ & 35 & Temporary crown \\
\hline 35 & XIVE ${ }^{\circledR}$ & 21 & $3.8 \times 11$ & 35 & Temporary crown \\
\hline
\end{tabular}

determined by three independent examiners who were not involved in the surgical procedure.

\section{Visual analog scale (VAS) evaluation of patient satisfaction} Patient satisfaction related to the esthetic outcome, pain, and swelling was measured with VAS by filling out a questionnaire at T3. Answers were recorded ranging from 0 to 10 labeled with " $0=$ totally unsatisfied, no pain, no swelling" and " $10=$ fully satisfied, extreme pain, extreme swelling" [34].

\section{Statistical analysis}

Data analysis was performed using SPSS 16.0 software (SPSS Inc., Chicago, IL, USA). Results were demonstrated as the mean \pm standard deviation (SD). The t-test was used to compare the variables. $P<0.05$ was considered statistically significant.

\section{Results}

Overall, 70 patients ( 34 women, 36 men) with a mean age of $40.1 \pm 12.3$ were included in the present retrospective study and they received a total number of 80 
Table 3 Dimensional changes at $\mathrm{T} 2$ and $\mathrm{T} 3$ by CBCT measurements

\begin{tabular}{|c|c|c|c|c|}
\hline \multirow[t]{3}{*}{ Variable } & \multicolumn{2}{|l|}{6 months } & \multicolumn{2}{|l|}{12 months } \\
\hline & $\Delta \mathrm{OCl}$ & $\triangle \mathrm{ICH}$ & $\Delta \mathrm{OCl}$ & $\mathrm{IICH}$ \\
\hline & \multicolumn{2}{|l|}{ Mean $(\mathrm{mm})$} & \multicolumn{2}{|l|}{ Mean $(\mathrm{mm})$} \\
\hline MC group & $0.72 \pm 0.26$ & $1.62 \pm 0.84$ & $0.68 \pm 0.91$ & $1.55 \pm 1.05$ \\
\hline Bio-Oss group & $0.70 \pm 0.52$ & $1.57 \pm 0.88$ & $0.62 \pm 0.78$ & $1.49 \pm 0.90$ \\
\hline$P$ value & 0.90 & 0.88 & 0.87 & 0.66 \\
\hline
\end{tabular}

$\mathrm{OCl}$ indicated the thickness of the labial crest (including bone graft) at the level of implant shoulder

$\mathrm{ICH}$ indicated the relative height of the labial crest at the level of implant shoulder

implants. There were no statistically significant differences in patient age, gender, smoking history, implant brand and implant site in two groups (Tables 1,2). According to Buser's criteria for successful osseointegration, all 80 implants remained well-integrated with a $100 \%$ implant survival rate after 1 year of permanent restoration. Furthermore, no significant differences were seen in bone graft types within the two groups.

\section{Radiographic outcomes}

The alveolar bone in both groups showed insignificant differences in horizontal and vertical bone loss at T2 and T3. As the specific data demonstrated in Table 3, the differences of $\mathrm{OCI}$ and $\mathrm{ICH}$ between the MC group $(0.72 \pm 0.26 \mathrm{~mm}, 1.62 \pm 0.84 \mathrm{~mm})$ and the Bio-Oss group $(0.70 \pm 0.52 \mathrm{~mm}, 1.57 \pm 0.88 \mathrm{~mm})$ were statistically no significant at T2. Similar results occurred at T3. The reduction of $\mathrm{OCI}$ and $\mathrm{ICH}$ were $0.68 \pm 0.91 \mathrm{~mm}$ and $1.55 \pm 1.05 \mathrm{~mm}$ in $\mathrm{MC}$ group, and the Bio-Oss group showed $0.62 \pm 0.78 \mathrm{~mm}$ and $1.49 \pm 0.90 \mathrm{~mm}$ loss in OCI and $\mathrm{ICH}$.

In addition, compared $\mathrm{T} 2$ to $\mathrm{T} 3$, the resorption of alveolar bone at horizontal distance (OCI) and vertical distance ( $\mathrm{ICH})$ in $\mathrm{MC}$ group or in Bio-Oss group had no statistically significant.
Table 5 The outcomes of patient satisfaction

\begin{tabular}{llll}
\hline & $\begin{array}{l}\text { MC group } \\
\text { Mean } \pm \text { SD }\end{array}$ & $\begin{array}{l}\text { Bio-Oss group } \\
\text { Mean } \pm \text { SD }\end{array}$ & $p$ value \\
\hline VAS score & $8.56 \pm 1.12$ & $8.27 \pm 1.44$ & 0.538 \\
\hline
\end{tabular}

\section{Esthetic outcomes}

Overall, none of the five parameters of the PES, or the total PES $(6.07 \pm 1.62$ vs. $6.13 \pm 1.41)$ values were significantly different when comparing the $\mathrm{MC}$ and the Bio-Oss group 1 year after crown placement (Table 4). What's more, the percentage of clinical acceptance was $60 \%$ in both groups.

\section{VAS outcomes}

Patient satisfaction estimated by VAS was similar $(8.56 \pm 1.12$ vs. $8.27 \pm 1.44)$, and the difference was not statistically significant $(P=0.538$; Table 5$)$ between the two groups.

\section{Discussion}

In this retrospective study, our hypothesis was that application of MC in IIP could achieve a similar effect as BioOss. The results revealed that no significant differences were found in terms of clinical and radiographic assessments, as well as esthetic outcomes and patient satisfaction at 12 months after permanent restoration. Therefore, our hypothesis for this study was accepted.

It is well known that buccal bone was concerned to be one of the most important features when it comes to get satisfying aesthetic results. It has also been claimed that the "critical thickness" value to the buccal bone should be at least $2 \mathrm{~mm}$ thick [35]. In addition, bone grafting materials in combination with IIP achieved better osseointegration in comparison to a situation where IIP was done without bone grafting [36]. Therefore, the chosen grafting materials to solve bone defect for new bone formation should be concerned at present.

Table 4 Comparison of PES values at T3 after crown placement

\begin{tabular}{|c|c|c|c|c|c|c|c|}
\hline \multirow[t]{2}{*}{ Group } & Mesial papilla & Distal papilla & $\begin{array}{l}\text { Curvature } \\
\text { of facial } \\
\text { mucosa }\end{array}$ & $\begin{array}{l}\text { Level of facial } \\
\text { mucosa }\end{array}$ & $\begin{array}{l}\text { Root convexity/ } \\
\text { soft tissue color and } \\
\text { texture }\end{array}$ & $\begin{array}{l}\text { Total score } \\
\text { (maximum10) }\end{array}$ & \multirow[t]{2}{*}{$\begin{array}{l}\text { Acceptable } \\
(100 \%)\end{array}$} \\
\hline & Mean \pm SD & Mean \pm SD & Mean \pm SD & Mean \pm SD & Mean \pm SD & Mean \pm SD & \\
\hline MC group & $1.13 \pm 0.74$ & $1.27 \pm 0.59$ & $0.87 \pm 0.52$ & $1.40 \pm 0.74$ & $1.40 \pm 0.63$ & $6.07 \pm 1.62$ & $60 \%$ \\
\hline Bio-Oss group & $1.2 \pm 0.77$ & $1.20 \pm 0.68$ & $0.93 \pm 0.70$ & $1.33 \pm 0.72$ & $1.47 \pm 0.64$ & $6.13 \pm 1.41$ & $60 \%$ \\
\hline$p$ value significance & $0.81, \mathrm{~ns}$ & $0.78, \mathrm{~ns}$ & $0.77, \mathrm{~ns}$ & $0.80, \mathrm{~ns}$ & $0.81, \mathrm{~ns}$ & $0.91, \mathrm{~ns}$ & \\
\hline
\end{tabular}

Clinical acceptability was defined as PES $\geq 6$

ns non-significant 
Bio-Oss ${ }^{\circledR}$ deproteinized bovine bone with excellent characteristic of osteoconductive property, high biocompatibility, and low biodegradation rate has been described as the most successful bone substitute worldwide and remains the best choice in a variety of graft materials.

Biomimetic artificial MC designed by Cui and his coworkers is an artificial bone graft which mimics composition and microstructure of human natural bone [26, 37]. Its remarkable treatment effect on bone defect reparation has been confirmed in more than 200,000 cases in clinical area of orthopedics, stomatology, neurosurgery and so on [27]. Many in vitro animal studies also have been verified the biocompatibility, biodegradability and osteoconductive potency of MC [38, 39]. For example, Ghate et al. demonstrated that $\mathrm{MC}$ applied for the patient with collapse and subluxation of metatarsal-cuneiform joint acted as an excellent alternative to autograft in fusing the podarthral joints with internal fixation [40]. Liu et al. also investigated the effect of $\mathrm{MC}$ on the rabbit rib defect, and reported that the $\mathrm{MC}$ group showed a higher bone remodeling activity in comparison with blank control group [41]. Moreover, $\mathrm{Wu}$ et al. proved that osteogenic differentiation on MC incorporated in poly bone cement was more than two times higher than that of poly alone after culturing for 21 day in human marrow mesenchymal stem cells culture system [42]. The result confirmed the important mechanism on osteogenic properties of MC at cellular level.

Preferably, bone grafts should be gradually degraded and replaced with newly-formed bone. As previous literature has reported, MC bone grafts should be a promising alternative for bone augmentation in oral surgeries. To the best of our knowledge, there are no available studies to confirm the effect of MC in promoting bone regeneration in the treatment of IIP. Therefore, in the present study, we firstly used the biomimetic $\mathrm{MC}$ as bone grafting material. As results shown above, 70 patients had been treated with 80 implants, and the implant survival rate was $100 \%$ in both groups. Additionally, the radiographic analysis revealed that no significant difference in bone reduction between the two groups at T2 and T3. Furthermore, the results of esthetic and patient satisfactory were also consistent with radiographic findings. Similarly, Wang et al. compared the clinical and histologic effect of Bio-Oss and MC bone materials on minipig, and found that the $\mathrm{MC}$ achieved the similar result as Bio-Oss [43]. Although there is no investigation comparing the efficacy of MC with that of Bio-Oss in IIP, our findings were similar to the results of studies above.
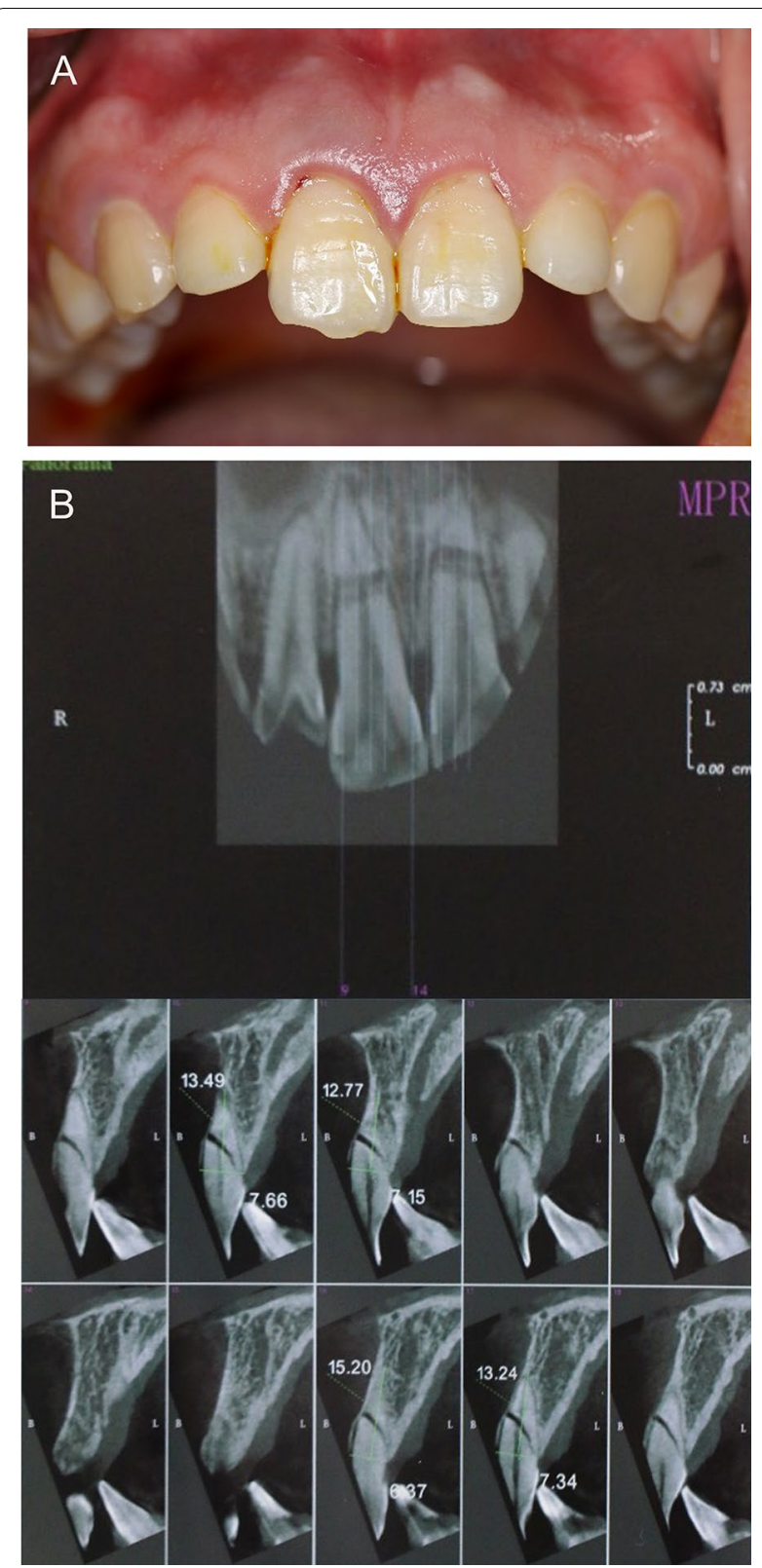

Fig. 2 Preoperative view. A Intraoral photograph, B preoperative $\mathrm{CBCT}$

Nevertheless, the present study has some limitations, including small sample size $(\mathrm{n}=70)$, short follow-up period, and lack of bone biopsy for histological evidence. Within its limits, further studies with larger sample sizes and long-term investigation are required for corroboration of these findings.

\section{Conclusions}

In conclusion, this study demonstrated that the biomimetic MC showed a similar behaviour as Bio-Oss not only in its dimensional tissues changes but also in clinical 

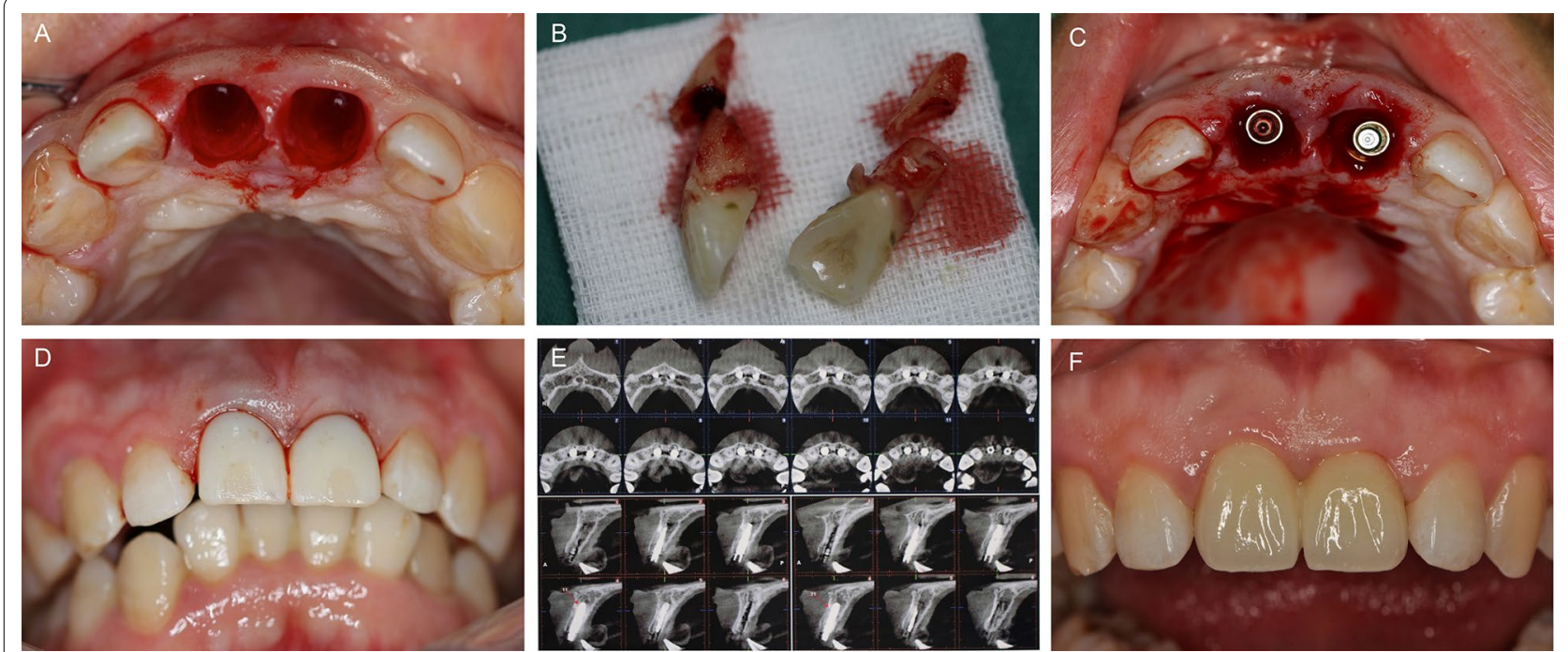

Fig. 3 Demonstration of the details of the process. A Atraumatic extraction of 11, 22, B extracted crown and root fragments, $\mathbf{C}$ immediate implant placement, $\mathbf{D}$ the temporary crown immediately after operation, $\mathbf{E}$ postoperative $C B C T$, $\mathbf{F}$ permanent restoration

acceptability and patient satisfaction. Within the limitations of this study, these cases show that MC could be considered as an alternative bone graft in IIP.

\section{Case report}

A 28-year-old healthy female with root-fractured anterior teeth was referred to our hospital. The teeth (\#11, \#21) showed $2^{\circ}$ mobility and had slight tenderness on percussion. Radiographic examinations revealed that \#11 and \#21 were root-fractured at the apical third (Fig. 2).

Considering the region of high esthetic value and patient's bone quantity, we decided to proceed with implanting \#11, \#21 immediately after teeth extraction, using XIVE $^{\circledR}$ implant system $\left(\right.$ XIVE $^{\circledR}$, Dentsply Friadent, Mannheim, Germany) replacement and $\mathrm{MC}$ for bone augmentation. Afterwards, the patient was treated by immediate reconstruction and permanent restoration was fixed 4 months postoperatively (Fig. 3A-F).

\section{Acknowledgements}

None.

\section{Authors' contributions}

YD designed this study and drafted the initial manuscript. JX participated in performing the research and in data analysis. X-HH and F-ZC participated in interpretation of data and critical review of the manuscript. D-SZ, S-YH conceptualized the study and drafted the initial manuscript. All authors have read and approved the final manuscript.

\section{Funding}

This study was funded by China Postdoctoral Science Foundation Grant (No. 2019M652380), and Haiyan Project of Lianyungang (No. KD2019lyghy001). The above funds were used for deduction some medical expenses of preparation of the preliminary study, data processing and analysis, and article polishing.

\section{Availability of data and materials}

All the datasets and materials used and analyzed during the current study are included in this published article. The datasets used and analyzed during the current study are available from the corresponding author on reasonable request.

\section{Declarations}

\section{Ethics approval and consent to participate}

This study was approved by the institutional review board of Shandong Provincial Hospital (SWYX: No. 2018-294) and complied with the tenets of the Declaration of Helsinki. Written or verbal informed consent was waived by Shandong Provincial Hospital ethics committee due to the retrospective nature of the study, and all data were analyzed anonymously. No administrative permissions were acquired by the research team to access the data used in our research.

\section{Consent for publication}

Not applicable.

\section{Competing interests}

The authors declare that they have no competing interests.

\section{Author details}

'Department of Oral and Maxillofacial Surgery, Zibo Central Hospital, Zibo 255036, China. ${ }^{2}$ Department of Basic Medicine, Kangda College of Nanjing Medical University, Lianyungang 222000, China. ${ }^{3}$ Department of Prosthodontics, Shandong Provincial Hospital Affiliated to Shandong First Medical University, Jinan 250021, Shandong, China. ${ }^{4}$ State Key Laboratory of New Ceramics and Fine Processing, School of Materials Science and Engineering, Tsinghua University, Beijing 100084, China. ${ }^{5}$ Department of Oral and Maxillofacial Surgery, Shandong Provincial Hospital Affiliated to Shandong First Medical University, Jinan 250021, Shandong, China.

Received: 22 February 2021 Accepted: 21 July 2021

Published online: 10 August 2021 


\section{References}

1. Hammerle CH, Chen ST, Wilson TG Jr. Consensus statements and recommended clinical procedures regarding the placement of implants in extraction sockets. Int J Oral Maxillofac Implants. 2004;19(Suppl):26-8.

2. Schultz AJ. Guided tissue regeneration (GTR) of nonsubmerged implants in immediate extraction sites. Pract Periodontics Aesthet Dent. 1993:5(2):59-65 (quiz 66).

3. Gelb DA. Immediate implant surgery: three-year retrospective evaluation of 50 consecutive cases. Int J Oral Maxillofac Implants. 1993;8(4):388-99.

4. Rosenquist B, Grenthe B. Immediate placement of implants into extraction sockets: implant survival. Int J Oral Maxillofac Implants. 1996;11(2):205-9.

5. Schwartz-Arad D, Chaushu G. The ways and wherefores of immediate placement of implants into fresh extraction sites: a literature review. J Periodontol. 1997;68(10):915-23.

6. Becker W, Clokie C, Sennerby L, Urist MR, Becker BE. Histologic findings after implantation and evaluation of different grafting materials and titanium micro screws into extraction sockets: case reports. J Periodontol. 1998:69(4):414-21.

7. Schwartz-Arad D, Chaushu G. Immediate implant placement: a procedure without incisions. J Periodontol. 1998;69(7):743-50.

8. Wilson TG Jr, Schenk R, Buser D, Cochran D. Implants placed in immediate extraction sites: a report of histologic and histometric analyses of human biopsies. Int J Oral Maxillofac Implants. 1998;13(3):333-41.

9. Cornelini R, Scarano A, Covani U, Petrone G, Piattelli A. Immediate onestage postextraction implant: a human clinical and histologic case report. Int J Oral Maxillofac Implants. 2000;15(3):432-7.

10. Kan JY, Rungcharassaeng K. Immediate placement and provisionalization of maxillary anterior single implants: a surgical and prosthodontic rationale. Pract Periodontics Aesthet Dent. 2000;12(9):817-24 (quiz 826)

11. Rosenquist $B$, Ahmed $M$. The immediate replacement of teeth by dental implants using homologous bone membranes to seal the sockets: clinical and radiographic findings. Clin Oral Implant Res. 2000;11(6):572-82.

12. Schwartz-Arad D, Gulayev N, Chaushu G. Immediate versus non-immediate implantation for full-arch fixed reconstruction following extraction of all residual teeth: a retrospective comparative study. J Periodontol. 2000;71(6):923-8.

13. Paolantonio M, Dolci M, Scarano A, et al. Immediate implantation in fresh extraction sockets. A controlled clinical and histological study in man. J Periodontol. 2001;72(11):1560-71.

14. Schultes G, Gaggl A. Histologic evaluation of immediate versus delayed placement of implants after tooth extraction. Oral Surg Oral Med Oral Pathol Oral Radiol Endod. 2001;92(1):17-22.

15. den Hartog L, Slater JJ, Vissink A, Meijer HJ, Raghoebar GM. Treatment outcome of immediate, early and conventional single-tooth implants in the aesthetic zone: a systematic review to survival, bone level, soft-tissue, aesthetics and patient satisfaction. J Clin Periodontol. 2008;35(12):1073-86.

16. Esposito M, Grusovin MG, Polyzos IP, Felice P, Worthington HV. 2010) Interventions for replacing missing teeth: dental implants in fresh extraction sockets (immediate, immediate-delayed and delayed implants. Cochrane Database Syst Rev. 2010;9:CD005968.

17. Chen ST, Buser D. Clinical and esthetic outcomes of implants placed in postextraction sites. Int J Oral Maxillofac Implants. 2009;24(Suppl):186-217.

18. Esposito M, Grusovin MG, Polyzos IP, Felice P, Worthington HV. Timing of implant placement after tooth extraction: immediate, immediate-delayed or delayed implants? A cochrane systematic review. Eur J Oral Implantol. 2010;3(3):189-205

19. Tarnow DP, Chu SJ, Salama MA, et al. Flapless postextraction socket implant placement in the esthetic zone: part 1. The effect of bone grafting and/or provisional restoration on facial-palatal ridge dimensional change - a retrospective cohort study. Int J Periodontics Restorative Dent. 2014;34(3):323-31

20. Urban IA, Jovanovic SA, Lozada JL. Vertical ridge augmentation using guided bone regeneration (GBR) in three clinical scenarios prior to implant placement: a retrospective study of 35 patients 12 to 72 months after loading. Int J Oral Maxillofac Implants. 2009;24(3):502-10.

21. Al Yafi F, Alchawaf B, Nelson K. What is the optimum for alveolar ridge preservation? Dent Clin North Am. 2019;63(3):399-418.

22. Wallace SC, Snyder MB, Prasad H. Postextraction ridge preservation and augmentation with mineralized allograft with or without recombinant human platelet-derived growth factor BB (rhPDGF-BB): a consecutive case series. Int J Periodontics Restorative Dent. 2013:33(5):599-609.
23. Hammerle CH, Araujo MG, Simion M, Osteology CG. Evidence-based knowledge on the biology and treatment of extraction sockets. Clin Oral Implant Res. 2012;23(Suppl 5):80-2

24. Mardas N, Trullenque-Eriksson A, MacBeth N, Petrie A, Donos N. Does ridge preservation following tooth extraction improve implant treatment outcomes: a systematic review: group 4: therapeutic concepts \& methods. Clin Oral Implant Res. 2015;26(Suppl 11):180-201.

25. Misawa M, Lindhe J, Araujo MG. The alveolar process following single-tooth extraction: a study of maxillary incisor and premolar sites in man. Clin Oral Implant Res. 2016;27(7):884-9.

26. Liao SS, Cui FZ, Zhang W, Feng QL. Hierarchically biomimetic bone scaffold materials: nano-HA/collagen/PLA composite. J Biomed Mater Res B Appl Biomater. 2004;69(2):158-65.

27. Peng C, Wang HP, Yan JH, Song TX. Locking system strengthened by biomimetic MC putty for the treatment of osteoporotic proximal humeral fractures. Regen Biomater. 2017:4(5):289-94.

28. Feng $L$, Zhang $L$, Cui $Y$, et al. Clinical evaluations of $M C$ in the extraction sites preservation. Regen Biomater. 2016;3(1):41-8.

29. Gluckman H, Pontes CC, Du Toit J. Radial plane tooth position and bone wall dimensions in the anterior maxilla: a CBCT classification for immediate implant placement. J Prosthet Dent. 2018;120(1):50-6.

30. Buser D, Chappuis V, Belser UC, Chen S. Implant placement post extraction in esthetic single tooth sites: when immediate, when early, when late? Periodontol 2000. 2017;73(1):84-102.

31. Buser D, Weber HP, Lang NP. Tissue integration of non-submerged implants. 1-year results of a prospective study with 100 ITI hollow-cylinder and hollow-screw implants. Clin Implants Res. 1990;1(1):33-40.

32. Yang X, Zhou T, Zhou N, Man Y. The thickness of labial bone affects the esthetics of immediate implant placement and provisionalization in the esthetic zone: a prospective cohort study. Clin Implant Dent Relat Res. 2019:21(3):482-91.

33. Belser UC, Grutter L, Vailati F, Bornstein MM, Weber HP, Buser D. Outcome evaluation of early placed maxillary anterior single-tooth implants using objective esthetic criteria: a cross-sectional, retrospective study in 45 patients with a 2- to 4-year follow-up using pink and white esthetic scores. J Periodontol. 2009;80(1):140-51.

34. Seymour RA, Charlton JE, Phillips ME. An evaluation of dental pain using visual analogue scales and the Mcgill Pain Questionnaire. J Oral Maxillofac Surg. 1983;41(10):643-8.

35. Spray JR, Black CG, Morris HF, Ochi S. The influence of bone thickness on facial marginal bone response: stage 1 placement through stage 2 uncovering. Ann Periodontol. 2000;5(1):119-28.

36. Ogunsalu C, Ezeokoli C, Archibald A, et al. Comparative study of osteoblastic activity of same implants (Endopore) in the immediate extraction site utilizing single photon emission computerized tomography: peri-implant autogeneous bone grafting with GTR versus no peri-implant bone grafting - experimental study in pig model. West Indian Med J. 201 1;60(3):336-9.

37. Qiu ZY, Cui Y, Tao CS, et al. MC: rationale, current status, and clinical applications. Materials. 2015:8(8):4733-50.

38. Liao SS, Guan K, Cui FZ, Shi SS, Sun TS. Lumbar spinal fusion with a MC matrix and rhBMP-2 in a rabbit model. Spine. 2003;28(17):1954-60.

39. Sun Y, Wang C, Chen Q, et al. Effects of the bilayer nano-hydroxyapatite/ MC-guided bone regeneration membrane on site preservation in dogs. J Biomater Appl. 2017;32(2):242-56.

40. Ghate NS, Cui H. MC artificial bone repair material products used for fusing the podarthral joints with internal fixation-a case report. Regen Biomater. 2017;4(5):295-8.

41. Liu FZ, Wang DW, Zhang YJ, et al. Comparison of rabbit rib defect regeneration with and without graft. J Mater Sci Mater Med. 2017;28(1):2.

42. Wu J, Xu S, Qiu Z, et al. Comparison of human mesenchymal stem cells proliferation and differentiation on poly(methyl methacrylate) bone cements with and without MC incorporation. J Biomater Appl. 2016;30(6):722-31.

43. Piao W, Yao Y, Hao Z, Ju-li P, Fu-zhai C, Ya-juan G. Repair of bone defect by using MC materials and collagen membrane in minipig models. China J Oral Maxillofac Surg. 2017;15(5):408-12.

\section{Publisher's Note}

Springer Nature remains neutral with regard to jurisdictional claims in published maps and institutional affiliations. 